\title{
SOBERANIA E MEIO AMBIENTE: A ADEQUAÇÃO DO DIREITO INTERNACIONAL ÀS NOVAS NECESSIDADES DE GESTÃO AMBIENTAL E OS MECANISMOS DA ONU PARA RESOLUÇÃO DE CONFLITOS
}

\author{
Flávio Paulo Meirelles Machado*
}

\section{Introdução}

Por ser um tema crucial, a globalização possibilitou aos seres humanos a conscientização de que todos os atos do homem podem afetar não somente a si mesmo, mas também aos inúmeros atores presentes no meio ambiente.

Globalização é, na verdade, uma mutação crescente na geopolítica mundial. Seu sintoma mais visível é o constante aumento do entrelaçamento dos povos, envolvendo rede de interdependência $^{1}$ continentais, ligadas pela circulação e influência de capital e bens, de informação e idéias, de pessoas e forças, e, também, pelo meio ambiente. ${ }^{2}$

Atualmente as fronteiras políticas não definem o que está cercado por seu poder do que não está. Hoje vivemos em uma "civilização genuinamente transnacional” ${ }^{3}$ De fato, há o desaparecimento das fronteiras nacionais, pois os Estados deixam de limitar as ações dos indivíduos, perdendo o controle sobre grande parte de suas ações.

Dentro da perspectiva de problemas ambientais, como resultados da globalização, não que a ordem ambiental possa ser enquadrada somente em um evento transnacional, fruto da globalização, é obvio que esses problemas são antrópicos e naturais.

O que é mais importante se constatar é que as ações do homem e da natureza excedem o conceito geopolítico de território: um problema ambiental, em um país, em pouco tempo, pode afetar outras nações vizinhas, ou, até mesmo, Estados em continentes diferentes. Verifica-se que a depreciação da camada de ozônio, o aquecimento global, a poluição são problemas globais que não podem ser contidos nem solucionados por um único Estado. Ou

\footnotetext{
* Bolsista da UNITAR. United Nations Institute for Training and Research.

${ }^{1}$ Para Keohane e Nye, globalização é a intensificação do que esses autores descrevem como interdependência. Para eles, de maneira simplória interdependência significa situações caracterizadas por efeitos recíprocos entre atores em diferentes países. KEOHANE, Robert; NYE, Joseph. Power and Interdependece. 3.ed. London: Logman, 2001,p.7.

${ }^{2}$ KEOHANE, Robert; NYE, Joseph. Power and Interdependence. London, Logman: 2001, p.229.

${ }^{3}$ MATTOS, Adherbal Meira. Direito, Soberania e Meio Ambiente. Rio de Janeiro: Destaque, 2001, p.35.
} 
seja, muitos dos problemas globais implicam soluções políticas internacionais, como, por exemplo, o Protocolo de Montreal, relativo às substâncias que destroem a camada de ozônio.

Dessa forma a questão é como gerir corretamente, ou sustentavelmente, o meio ambiente em um mundo globalizado. A utilização de axiomas tradicionais, tais como a teoria da balança de poder ou a imaginária segurança nacional, para análise dos problemas econômicos ou ecológicos da interdependência é falha. ${ }^{4}$ Conseqüentemente, assim com os demais axiomas tradicionais, seria o conceito tradicional de Soberania encontrado na ordem internacional, em um mundo sem fronteiras, incapaz de corresponder às necessidades do planeta?

No entanto, os meios políticos atuais não permitem que haja um único sistema mundial de proteção ao meio ambiente. O modelo tradicional de Estados soberanos, tendo em vista sua limitação instrumental, ainda é a forma vigente de organização do direito internacional. A solução encontrada, portanto, tem sido a cooperação entre os Estados, e a tentativa de conscientização de todos os atores envolvidos acarretando a responsabilidade perante a Humanidade em proteger o meio ambiente.

Prevendo isso, a Declaração de Estocolmo enfatiza que em questões relativas ao meio ambiente “os países, [...] devem ocupar-se com espírito de cooperação [...] respeitando a soberania e os interesses de todos os Estados." 5

Dessa forma, o objetivo central da primeira parte desse trabalho é versar sobre a compatibilidade entre o princípio da Soberania concernente com a responsabilidade ambiental dos Estados. Na segunda parte deste pretende-se apresentar, de forma sucinta, o sistema da família ONU para resolução de controvérsias ambientais entre Estado soberanos. Por último, a análise da ordem ambiental atual, a posição em que se encontra o direito ambiental internacional com relação à proteção ao meio ambiente e às formas tradicionais do direito.

\section{0 conflito entre o princípio da soberania dos Estados e a responsabilidade de proteção ambiental}

\subsection{Soberania}

Em sentindo amplo, o conceito político-jurídico de Soberania pode ser indicado como “o poder de mando de última instância, numa sociedade política.” 6 Ademais, a

\footnotetext{
${ }^{4}$ KEOHANE, Robert; NYE, Joseph. Power and Interdependece. 3.ed. London: Logman, 2001, p.7.

${ }^{5}$ Princípio 24 da Declaração de Estocolmo Sobre Meio Ambiente Humano de 1972. 
Soberania é a racionalização do uso dos recursos jurídicos, pretendendo-se compor força e poder, em poder de direito. Em outras palavras, aliar o poder de fato à legitimidade política. Entende-se desse espectro político-jurídico a possibilidade do Estado, mediante seus mecanismos internos, manter a concentração de poder, tendo o objetivo de realizar a sua máxima unificação política. ${ }^{7}$

Segundo o professor Alexandre Kiss, a Soberania pode ser entendida como a exclusividade de jurisdição de um Estado em seu território, ou seja, “o Estado é a única autoridade competente para estipular obrigações legais em seu território, possui o poder executivo e seus tribunais são os únicos competentes para julgarem litígios”. ${ }^{8}$

Essa definição evidencia uma das faces da Soberania, a interna. Isto é, a centralização do poder para a eliminação dos conflitos internos, como no caso da guerra privada, a fim de manter a paz.

A segunda é a externa, a qual, na visão da teoria realista das relações internacionais, constitui-se na obrigação do uso da força, em última instância, pelos Estados para equilibrarem a balança de poder. Entretanto, essas relações internacionais de poder, progressivamente, têm sido disciplinadas pelo direito internacional. ${ }^{9}$

Na visão tradicionalista do direito internacional público, os Estados são os únicos atores legais nas relações internacionais; são soberanos em seu território, achando-se em nível de igualdade com os demais Estados, não devendo submissão a qualquer ente político global. ${ }^{10} \mathrm{O}$ artigo 2, § 7 da Carta da ONU confirma este princípio: nenhum Estado é obrigado a se submeter a qualquer intervenção em assuntos domésticos. ${ }^{11}$

Segundo Hobbes, a legalização desse monopólio do uso da força pelos Estados encontra-se no contrato social, entretanto seus sucessores confundiram o monopólio de aplicar

\footnotetext{
${ }^{6}$ MATTEUCI In: BOBBIO Norberto; MATTEUCI Nicola e PASQUINO Gianfranco. Dicionário de Política. 5.ed. Brasília: Editora Universidade de Brasília, 2000, p. 1179.

${ }^{7}$ MATTEUCI In: BOBBIO Norberto; MATTEUCI Nicola e PASQUINO Gianfranco. Dicionário de Política. 5ºd. Brasília: Editora Universidade de Brasília, 2000, p.1179.

${ }^{8}$ Texto original: "In other terms, the State is the only authority which can adopt obligatory legal rules for its territory, has the executive power (administration, police) and its tribunals are the only ones competent to judge litigation.” (KISS, Alexandre. Introduction to International Environmental Law. Genebra, Suíça: UNITAR, 1997, p.72.) (Todas traduções deste artigo são de toda minha responsabilidade)

${ }^{9}$ Visão realista mais especificamente do francês Raymond Aron.

10 "The consequence of the exclusive power of States on their territory is that no other public authority, be it another State or an intergovernmental organization, has the right to intervene in the realm of its exclusive competence." (KISS, Alexandre. Introduction to International Environmental Law. Genebra, Suíça: UNITAR, 1997, p.72.)

${ }^{11}$ Texto original. "Nenhum dispositivo da presente Carta autorizará as Nações Unidas a intervirem em assuntos que dependam essencialmente da jurisdição de qualquer Estado ou obrigará os Membros a submeterem tais assuntos a uma solução, nos termos da presente Carta [...]”.
} 
sanção com a capacidade de se fazer obedecer pelo uso da violência, ou seja, reduziram o uso da força e a Soberania à mesma esfera de poder, conduzindo as relações a um poder sem direito, quebrando o vínculo político-jurídico. ${ }^{12}$

Em contrapartida, observa-se outra fórmula de desequilíbrio da Soberania: o direito sem poder, isto é, a identificação do poder legislativo extremado na visão da vontade geral, em que o soberano faz somente a vontade do povo.

Do ponto de vista teórico, verifica-se a partir das visões mencionadas a existência de algumas características da Soberania. Seria ela indivisível, perpétua e absoluta? Quanto à visão da teoria do estado misto ${ }^{13}$, para a legitimidade da Soberania é preciso a validade das leis. Verifica-se que o objetivo fundamental de qualquer sistema jurídico é a proteção de valores reconhecidos como essenciais na sociedade. ${ }^{14}$ No que concerne à lei no Estado Moderno de Direito, as normas são adotadas através de procedimentos aceitos como válidos e o caráter obrigatório da lei restringe os comportamentos danosos. ${ }^{15}$

A lei torna-se cada vez mais o principal instrumento de organização social. ${ }^{16}$ Dessa forma, através do contrato social - modernamente, usando-se da Constituição - põe-se um freio jurídico à Soberania, proclamando novos direitos e valores fundamentais das sociedades. Considerando a divisão de poder como válida, desde que percorrido o devido processo constituinte, possibilita-se a divisão da Soberania entre os representantes legais e o povo desde que essa faculdade esteja previamente pactuada. ${ }^{17}$

O pensamento político de Locke, apesar de proteger a tese que a Soberania é “o poder máximo”, afirma que o soberano deve usar de seu poder em combinação com o que foi constituído em contrato. Tal conceito proporciona que, independentemente da Soberania ser do povo ou do representante, este poder encontra-se prisioneiro do ordenamento jurídico e somente ele prevê quem pode legislar e quem pode utilizar-se da violência legal. ${ }^{18}$

\footnotetext{
${ }^{12}$ MATTEUCI In: BOBBIO Norberto; MATTEUCI Nicola e PASQUINO Gianfranco. Dicionário de Política. 5. ed. Brasília: Editora Universidade de Brasília, 2000, p. 1180.

13 Estado Misto é o Estado que possui o equilíbrio entre poder de direito (legal) e poder de fato (violência).

14 Todas as traduções são de minha exclusiva responsabilidade. Original:“a fundamental objetive of any legal system is to protect values recognized as essential within society.” (KISS, Alexandre. Introduction to International Environmental Law. Genebra, Suíça:UNITAR, 1997, p. 55.)

${ }^{15}$ KISS, Alexandre. Introduction to International Environmental Law. Genebra, Suíça: UNITAR, 1997, p. 6.

${ }^{16}$ Principal fonte em detrimento do costume já que uma lei pode ab-rogar um costume, enquanto o costume não ab-roga as leis, sobretudo no sistema positivista.

${ }^{17}$ Em visão pessoal, considero geograficamente a Soberania indivisível. E conjuntamente com a visão realista das relações internacionais, acredito que a voz do Estado seja unânime e homogênica internacionalmente; os processos políticos internos quando democráticos não afetam a síntese final da vontade soberana.

${ }^{18} \mathrm{O}$ constitucionalista Fernand Lassale adverte que a constituição não se resume à “[...] simples fatores de poder, mas sim a verdadeiro direito-instituições jurídicas. Quem atenta contra elas atenta contra a lei e por conseguinte
} 
Nas questões internas dos Estados, na realidade, faz pouco sentido comentar-se sobre Soberania, já que essa é, na verdade, limitada à constituição e caracterizada somente no momento da constituinte. Não que ela tenha desaparecido, mas é neutralizada pelos poderes internos de um Estado. Este é, de fato, o poder soberano, que:

[...] cria o ordenamento [...] a real Soberania do povo, que se manifesta no seu poder constituinte, pelo qual, através da constituição, define os órgãos e os poderes constituídos e instaura o ordenamento, onde estão previstas as regras que permitem sua transformação e sua aplicação. ${ }^{19}$

\subsection{Cenário internacional}

Quanto à abordagem da corrente realista: o cenário internacional é um sistema em que os Estados competem entre si pelo poder, e, é, basicamente, um sistema anárquico, sem governo ou autoridade suprema. Os Estados promovem seus interesses, não podendo recorrer a nenhuma autoridade para implementar lei ou direito internacional. Isso não significa uma desordem total, pelo contrário, a racionalidade e unanimidade (homogeneidade) promovem a ordem e a previsibilidade no comportamento dos Estados. Normalmente, esses observam e se conduzem pelos caminhos do direito internacional, não porque são bons, mas porque o direito internacional promove seus objetivos e lhes interessa serem percebidos como respeitadores do direito e encorajar outros ao mesmo. ${ }^{20} 21$

O mesmo princípio de Soberania existe como mencionado, tanto na esfera internacional, como nacional, entretanto, suas características são diferenciadas por causa dos fatores de composição da ordem internacional e nacional. De convenção com o princípio 21 da Declaração de Estocolmo: Os Estados possuem de acordo com a Carta das Nações Unidas

é punido[...]”( LASSALE, Ferdinand. A Essência da Constituição. 4. ed. São Paulo:Lúmen Iuris, 1998. p.20.) Categoricamente, o escritor escreve que, na visão tradicional, a constituição "é um pacto juramentado, entre o rei e o povo, estabelecendo princípios alicerçais de legislação e do governo dentro de um país” e que para os republicanos "[...] a constituição é lei fundamental proclamada pela nação, na qual baseia-se a organização do direito público do país.” (LASSALE, Ferdinand. A Essência da Constituição. 4.ed. São Paulo:Lúmen Iuris, 1998, p.6.)

${ }^{19}$ MATTEUCI In: BOBBIO Norberto; MATTEUCI Nicola e PASQUINO Gianfranco. Dicionário de Política. 5ed. Brasília: Editora Universidade de Brasília, 2000, p. 1185.

${ }^{20}$ VIOTTI, Paul R; KAUPI, Mark V. Internacional Relations Theory: Realism, Pluralism, Globalism, and Beyond. 3. ed. Boston: Prentice Hall, 1998, p.55.

${ }^{21}$ Edward Carr, adepto da mesma escola, quanto à natureza do direito internacional escreve: "O direito internacional difere do direito nacional dos estados modernos por ser o direito de uma comunidade nãodesenvolvida e não totalmente integrada. Não possui três instituições que são partes essenciais de qualquer sistema desenvolvido de direito nacional: um âmbito judiciário, um executivo e um legislativo." (CARR, Edward H. Vinte Anos de Crise. 2.ed. Brasília: EdUnb, 2001, p.221.) O escritor conclui em seu livro, aqui citado, que para descaracterizar a atual situação do direito internacional é preciso um "superestado". 
e com os princípios do direito internacional, o direito soberano de explorar seus próprios recursos em suas políticas ambientais. ${ }^{22}$

Contudo, no moderno cenário das relações internacionais, nas quais a interdependência entre os Estados tornou mais forte o caráter econômico e mais elaborado o caráter jurídico das ações estatais, desaparece a plenitude do poder estatal. Juntamente com isso, esvazia-se o papel do uso da força e do poder estatal, limitando a Soberania. O movimento de colaboração para construção de organismos internacionais e supranacionais começou, especialmente, desde o fim da segunda guerra e vem a desgastar o poderio tradicional dos Estados.

Nos dias atuais, os meios de comunicação de massa possibilitam a formação da opinião publica da comunidade internacional, que, por sua vez, exerce pressão nas ações do Estado. Ou seja, novas autoridades não tradicionais estão adentrando nas esferas de poder e, com isso, limitando a Soberania Estatal. Isto é, há maior disponibilidade de informação ao público em geral, derivando na maior consciência quanto às necessidades ambientais. Reconhecendo tais necessidades, gera-se uma onda internacional que se converte em pressão interna e externa nos Estados que força os governos a aderirem à proteção ambiental. Nesse sentido, o recente reconhecimento da proteção ao meio ambiente como um valor básico da comunidade internacional tem promovido o desenvolvimento do direito internacional como também integrou o direito ambiental à realidade internacional, contribuindo, reformulando e questionando as formas tradicionais de direito internacional. ${ }^{23}$

\subsection{Proteção ao meio ambiente}

Dentro desse novo cenário das relações internacionais, encontra-se um novíssimo braço da ciência jurídica, o direito internacional ambiental, que também expressa o princípio da soberania, como se examinará adiante.

O próprio termo “meio ambiente” é algo novo na linguagem jurídica e tornou-se conhecido somente nos últimos trinta anos. Meio ambiente delimita uma certa área ou, até

\footnotetext{
${ }^{22}$ O texto original. "Em conformidade com a Carta das Nações Unidas e com os princípios de direito internacional, os Estados têm o direito soberano de explorar seus próprios recursos em aplicação de sua própria política ambiental e a obrigação de assegurar-se de que as atividades que se levem a cabo, dentro de sua jurisdição, ou sob seu controle, não prejudiquem o meio ambiente de outros Estados ou de zonas situadas fora de toda jurisdição nacional”.

${ }^{23}$ KISS, Alexandre e SHELTON, Dinah. Developments and Trends in International Environmental Law. Genebra, Suíça:UNITAR, 1999, p. 96.
} 
mesmo, o planeta como um todo. É desta amplitude de espaço, onde se demarca o ecossistema ou meio ambiente, que nasce o conflito entre as ações estatais, pois a natureza não conhece limites políticos geográficos e as ações nocivas ao meio ambiente também podem extrapolar esses marcos.

Tal conjuntura gera inúmeras tensões internacionais, podendo até mesmo motivar conflitos armados, pois tendem a suscitar tensões entre as soberanias. Todavia, isso pode ser contornado pacificamente através do direito internacional.

O fundamento histórico do direito ambiental internacional está nessas disputas bilaterais entre Estados, como é o caso do Trail Smelter entre os EUA e o Canadá, onde se verificou que nenhum estado pode danificar o meio ambiente de outro. Adiante desse processo se averiguou que ao se abordar a proteção ambiental, é mister a utilização de instrumentos mais vastos ao invés de utilizar somente abordagens bilaterais. Por exemplo, o dever de proteger a vida, comanda como imprescindível o direito a um meio ambiente saudável para todos. Nesse sentido a comunidade internacional deparou-se com a responsabilidade conjunta de proteger a biosfera em sua totalidade, implicando que o direito internacional deva proteger o meio ambiente, até mesmo dentro dos territórios estatais, e salvaguardar os territórios fora do controle estatal, tal como ocorre com a Antártica. Isso sugere a responsabilidade dos Estados em proteger o meio ambiente interno, promover a cooperação com demais Estados e garantir que suas atividades não provoquem danos desnecessários à biosfera.

Inevitavelmente, o direito ambiental internacional é espécie do qual o Direito Internacional é gênero. A proteção ao meio ambiente precisa de instrumentos tradicionais empregados pelo direito internacional, tais como, o direito dos Tratados internacionais, o direito costumeiro, os princípios de soberania, da autodeterminação, da não-intervenção, direito comunitário, direito sobre o mar, e sistema de solução pacífica de controvérsia. Ao mesmo tempo, também precisa de novas formas de cooperação inter e intra-estatais para se possa solucionar novas demandas de proteção. Isso traz à tona certo choque com outros institutos do direito tradicional. Os resultados disso tudo são os esforços de harmonização do direito tradicional com o direito ambiental os quais geraram novos mecanismos jurídicos, tais como, a gestão compartilhada, a responsabilidade em comum, porém diferenciada e o desenvolvimento sustentável.

Pelo encargo que os tempos modernos trazem ao meio ambiente, a poluição, o desmatamento, a falta d’água potável, aquecimento global, desertificação, perda de 
biodiversidade, pobreza, o direito ambiental hoje questiona noções basilares dos Estados e suas interações com a comunidade internacional. Não somente sua relação com a sociedade internacional, mas com toda gama de atores da sociedade civil. A expansão desta disciplina é caracterizada pela interação e proliferação da consciência ambiental em todos os níveis da sociedade, adotando-se leis locais, regionais, globais e nacionais para a proteção da matéria. Do mesmo modo em que o direito internacional é influenciado, influencia essas abordagens, regionais e nacionais.

Especialistas em Direito Ambiental resumem que: “o impacto recíproco do desenvolvimento legal no campo da proteção ambiental pode ser visto como um aspecto da globalização, um passo em rumo à criação de um sistema unificado e harmonizado para a proteção do meio ambiente planetário. Claramente a tendência parece dirigir-se à criação e aplicação de normas e regras iguais em diferentes níveis de governança: global, regional e nacional."24

\subsection{Direito ambiental internacional e direito internacional}

Um dos costumes internacionais é o de não intervenção em assuntos domésticos de outros países, ou seja, observância da Soberania. As questões ambientais, porém, tendem a tocar todos os Estados como um todo. O princípio de exclusividade jurisdicional do Estado em seu território também prevê a garantia que atividades dentro de sua jurisdição não venham a sofrer danos de outros Estados. Tanto a Declaração do Rio e a Declaração de Estocolmo tentam resolver este impasse: confirmam o direito, impondo aos países que assumam a responsabilidade de garantir que atividades dentro de sua jurisdição não venham a lesar o meio ambiente de outro país.

Essa obrigação internacional acaba por impor limitações à liberdade de ação dos soberanos. Mas devemos advertir que ambas declarações ainda mantêm o princípio de soberania estatal, como princípio geral. Nenhum Estado é obrigado a adentrar-se em tratados/declarações/convenções, e cabe a cada um deles ratificar, segundo sua vontade e interesse, qualquer desses mecanismos internacionais. Deve-se respeitar o processo de

\footnotetext{
${ }^{24}$ KISS, Alexandre e SHELTON, Dinah . Developments and Trends in International Environmental Law. Genebra, Suíça: UNITAR, 1999, p. 9. (trad. minha) Quanto à forma de se elaborar tal sistema, os autores não deixam claro se sua visão é compatível com a idéia realista de um “superestado”. Todavia, é possível notar que os autores não possuem tendência a adotar uma visão ideológica quanto a esse assunto. Parece, nesse caso, que os autores fogem da idéia de ideologia por detrás da proteção ambiental, entendendo a necessidade de preservação ambiental, e a atual unificação das normas e regras ambientais como um resultado fim inevitável de um processo temporal e territorial (globalização).
} 
ratificação nos países de origens. Qualquer atitude no direito internacional deve ser fundamentada pela legitimidade (aprovação do povo) e legalidade (validade da norma). Mesmo que exista um costume internacional que possa ser considerado hard law, ainda assim, deve-se observar a vontade do povo e a legalidade desse princípio quanto a sua valoração pelas sociedades nacionais. Congruente a essa visão, René-Jean Dupuy entende que:

[...] os Estados, sujeitos do Direito Internacional, promulgam em comum, por meio de acordo, a regulamentação que exprime o interesse de todos, cabendo a cada um deles avaliar a dimensão do dever que lhe incumbe e as condições de sua execução. O Direito interno é um direito de subordinação que condiciona sujeitos susceptíveis de serem condicionados, se necessário pela força, à observância da lei, graças a um aparelho institucional adequado; o Direito Internacional, pelo contrário, constitui um direito de coordenação que se limita a favorecer a cooperação entre os Estados. Mas estes, não estando dependentes de nenhuma autoridade de sobreposição, unem-se apenas numa base voluntária e são soberanos na avaliação de seu próprio direito. ${ }^{25}$

Isso, de maneira alguma, compromete a imagem da lei internacional, mas certamente há relativa impossibilidade do caráter obrigatório das leis internacionais ${ }^{26}$. O direito internacional tem um papel necessário na estruturação das relações internacionais e, sobretudo, nas resoluções de conflitos internacionais. Ainda que o poder de fato dos Estados venham a sobrepor o poder legal, mesmo assim há necessidade das instituições legais internacionais. $^{27}$

Ambos, Kiss e Shelton, reconhecem que os Estados membros da ONU proclamam o "princípio da soberania" e o "princípio da igualdade"28. Além do mais, afirmam que inúmeras responsabilidades dos Estados no direito ambiental Internacional, tal como o

\footnotetext{
${ }^{25}$ DUPUY, René-Jean. O Direito Internacional. Coimbra, Almedina, 1993, pp 5-6.

${ }^{26}$ Segundo alguns autores há a possibilidade de adoção de “binding norms,” obrigar judicialmente um Estado. Segundo o professor Kiss algumas organizações possuem este poder. São elas: o Conselho de segurança das Nações Unidas, a Organização para Cooperação e Desenvolvimento Econômico e a União Européia.

27 Sobre a natureza do direito Internacional ambiental KISS e SHELTON comentam que: “These provisions indicate that some areas of domestic jurisdiction are no longer considered as the exclusive domain of states, a suggestion reinforced by the concept that at least some aspects of environmental protection are the common concern of humanity. These include the global climate, the ozone layer, and biological diversity. The proclamation of a common concern internationalizes the subject matter and necessarily removes it from exclusive domestic jurisdiction. It is also worth noting that most international environmental obligations have to be executed within the domestic domain. The examples are numerous and include such duties as authorizing the export or import of dangerous wastes, trade in endangered species or specific chemicals, and the adoption of measures for air or water pollution control.”(KISS, Alexandre e SHELTON, Dinah. Developments and Trends in International Environmental Law. Genebra, Suíça: UNITAR, 1999, p.97.)

${ }^{28}$ Texto original. Carta da ONU, artigo 2(1): “A Organização e seus membros, para a realização dos propósitos mencionados no Artigo 1, agirão de acordo com os seguintes Princípios: 1. A Organização é baseada no princípio da igualdade de todos os seus membros.”

Equidade e Soberania, para vários autores, incluindo Morgenthau, são sinônimos.
} 
princípio das responsabilidades comuns, porém diferenciadas, ${ }^{29}$ na realidade reflete um limite a Soberania. Em outras palavras, degenera a Soberania e a Igualdade. ${ }^{30}$

\subsection{Tratados internacionais ${ }^{31}$}

Uma das funções da lei necessária à vida civilizada é a de proteger os direitos que foram criados por contratos privados, concluídos numa forma reconhecida como válida pelo direito. O direito internacional defende, com algumas reservas, os direitos criados por tratados e acordos internacionais. Este princípio é essencial à existência de qualquer tipo de comunidade internacional e é [...] reconhecida em teoria por todos os estados. ${ }^{32}$

O tratado internacional é um instrumento jurídico que transmite e extingue direitos. É uma declaração consensual, emanada da livre vontade das partes, norma particular estabelecida pelas partes no acordo. A formalidade é essencial nos tratados, a forma escrita. ${ }^{33}$ Conforme Kiss e Shelton:

[...] [os tratados] na sua maioria expressão uma preocupação remota e geral, ao invés de interesses individuais ou coletivos imediatos: o objetivo é beneficiar toda humanidade, algo que só se pode obter através da cooperação internacional e aceitação de suas obrigações por todos os governos, mesmo que não haja retorno imediato. Eles procuram prever e eliminar situações as quais podem ameaçar a vida ou são contrárias os valores humanos elementares, e, criar condições mais benéficas para a vida de todos, incluindo as futuras gerações. ${ }^{34}$

Ao contrário do que se tem nos sistemas internos no campo do direito internacional, não existe constituição ou qualquer outra forma de codificação de leis internacionais obrigatórias aos Estados. As únicas entidades que podem exercer atividade legislativa entre os Estados são eles mesmos, ou seja, o progresso da proteção ambiental

29 “'Os Estados irão cooperar, em espírito de parceria global, para a conservação, proteção e restauração da saúde e da integridade do ecossistema terrestre. Considerando as diversas contribuições para a degradação do meio ambiente global, os Estados têm responsabilidades comuns, porém diferenciadas. Os países desenvolvidos reconhecem a responsabilidade que lhes cabe na busca internacional do desenvolvimento sustentável, tendo em vista as pressões exercidas por suas sociedades sobre o meio ambiente global e as tecnologias e recursos financeiros que controlam.”( Declaração do Rio, Princípio 7)

${ }^{30}$ KISS, Alexandre e SHELTON, Dinah. Developments and Trends in International Environmental Law. Genebra, Suíça: UNITAR, 1999, p.97.

${ }^{31}$ Tratado pode ser definido como: todo acordo formal concluído entre sujeitos de direito internacional público, e destinada a produzir efeitos jurídicos [...] as variantes terminológicas de tratado concebíveis em português: acordo, ajuste, arranjo, ata, ato, carta, código, compromisso, constituição, contrato, convenção, convênio, declaração, estatuto, memorando, pacto, protocolo e regulamento. Esses termos são de uso livre $e$ aleatório[...].(REZEK, José Francisco. Direito Internacional Público: curso elementar. 9.ed. São Paulo: Saraiva, 2002, p.14-16.)

${ }^{32}$ CARR, Edward H. Vinte Anos de Crise. 2.ed.Brasília: EdUnb, 2001, p.235.

${ }^{33}$ Ver. Convenção de Viena sobre o direito dos tratados, art 2(I, a).

${ }^{34}$ KISS, Alexandre e SHELTON, Dinah. Developments and Trends in International Environmental Law. Genebra, Suíça: UNITAR, 1999, p. 108. (trad. minha) 
internacional, hoje, encontra-se preso aos tratados e costumes internacionais, pois tais são os instrumentos materiais encontradas para lidar com a questão. O critério básico deste processo é a livre determinação e aceitação pelos Estados, sem que necessariamente haja ganho imediato ou qualquer reciprocidade das demais partes. ${ }^{35}$

Dissertando sobre a natureza dos contratos de natureza privada, resume que: "o contrato - instrumento de equidade, de justiça comutativa -, como linguagem jurídica, vem trazer a certeza e consecutivamente, a vigência necessária nos negócios jurídicos particulares, implementando, conseqüentemente, a segurança jurídica.” 36

Busca-se essa mesma segurança jurídica nos contratos internacionais. Para Morgenthau, “onde não existirem nem comunhão de interesses nem equilíbrio de poder, não haverá direito internacional.” ${ }^{37}$ Em outras palavras, através dos tratados, "instrumento de equidade”, pode haver uma manifestação dos interesses e equilíbrio do poder, expressão real da “segurança jurídica” objetivada pelos Estados. Entretanto, segurança jurídica na esfera internacional é limitada por falta de uma autoridade centralizadora. Por essa razão é que Morgenthau assegura que "uma ordem legal internacional descentralizada, e [é], portanto fraca e ineficaz.” 38

Existem quatro princípios fundamentais do regime de contratos: (a) o princípio da autonomia da vontade, conectado com a capacidade das partes em criarem e se sujeitarem a obrigações, reconhecidas e tuteladas pela ordem jurídica; (b) o princípio do consensualismo, o contrato é fonte de simples consentimento das partes; (c) o princípio da força obrigatória do contrato,- pacta sunt servanda, - trata-se de um instrumento como uma lei entre as partes, devendo ser obrigatório o cumprimento do mesmo; (d) o princípio da boa-fé expressa a lealdade entres as partes no cumprimento do estabelecido em contrato; e) o princípio da relatividade dos efeitos contratuais, o contrato gera efeitos somente entre as partes ou em terceiros beneficiados. ${ }^{39}$

Além desses quatro fundamentos não se pode deixar de mencionar que o princípio da relatividade dos efeitos contratuais, de certa forma, não é sempre observado no direito internacional. Por exemplo, a Carta da ONU expõe que: “A Organização fará com que os

\footnotetext{
${ }^{35}$ KISS, Alexandre e SHELTON, Dinah . Developments and Trends in International Environmental Law. Genebra, Suíça: UNITAR, 1999, p. 107.

${ }^{36}$ VIEIRA, Danilo Porfírio de Castro. Os Contratos na Gênese do Direito. Brasília: Ed Juares de Oliveira, 2004, p.85.

${ }^{37}$ MORGENTHAU. A Política entre as Nações. Brasília: Edunb, 2003, p.510.

${ }^{38}$ MORGENTHAU. A Política entre as Nações. Brasília: Edunb, 2003, p.510.

39 VIEIRA, Danilo Porfírio de Castro. Os Contratos na Gênese do Direito. Brasília: Ed Juares de Oliveira, 2004, p.82.
} 
Estados que não são membros das Nações Unidas hajam de acordo com esses princípios [os previstos na carta] em tudo quanto for necessário à manutenção da paz e da segurança internacionais.” 40 Hoje é majoritária a visão que acordos ambientais devam, pelo menos, impactar terceiros, já que a defesa do ecossistema precisa de participação satisfatória de todos os Estados. ${ }^{41}$

Ademais, no direito internacional, existe um quinto princípio fundamental dos contratos internacionais: o princípio rebus sic stantibus. Este se refere "à superveniência da impossibilidade do cumprimento do tratado, e, ainda, à alteração fundamental das circunstâncias.” 42

Para Carr, rebus sic stantibus "estaria implícita em todo tratado, ou seja, que as obrigações de um tratado só teriam eficácia, frente ao direito internacional, enquanto as condições que prevaleciam à época da conclusão do tratado continuassem." ${ }^{43} \mathrm{Na}$ realidade, o que essa cláusula permite é que a pacta sunt servanda não seja uma regra de direito válida sem exceção. No caso do direito internacional possibilita que quando há um desequilíbrio de poder entre as partes de um contrato, essas possam desmanchar o tratado. ${ }^{44}$

No caso de direito ambiental internacional, o princípio da responsabilidade comum, mas diferenciada, é a conseqüência do truísmo que nem todos os Estados possuem capacidade igual para proteger ao meio ambiente. O que permite os Estados utilizarem a cláusula rebus sic stantibus quando estes possuem dificuldade em cumprir com suas obrigações ambientais.

Já nos ramos tradicionais do direito internacional, como, por exemplo, no direito econômico internacional quando um Estado viola uma obrigação, em harmonia com o

\footnotetext{
${ }^{40}$ Carta da ONU. Artigo 2 (6).

${ }^{41}$ São exemplos disso: A CITES - Convenção sobre o Comércio Internacional das Espécies da Flora e da Fauna Selvagens em Perigo de Extinção - no artigo 10 exige documentação comparável às documentações estipuladas a países signatários. O artigo 4 do Protocolo de Montreal proíbe a importação e exportação de certas substâncias prejudiciais à Camada de Ozônio entre os paises signatários e não signatários.

42 REZEK, José Francisco. Direito Internacional Público: curso elementar. 9.ed. São Paulo: Saraiva, 2002, p.109.

${ }^{43}$ CARR, Edward H. Vinte Anos de Crise. 2.ed.Brasília: EdUnb, 2001, p.236.

${ }^{44}$ Infelizmente, de forma maligna, essa cláusula foi ligada ao princípio de "necessidade" ou dos "interesses vitais” das nações, uma vez que Hitler utilizou-se dessa cláusula para justificar suas atrocidades, referindo-se que sua nação estava em "perigo de opressão ou de aniquilação” causados pelos aliados que dominavam o mercado internacional e aplicavam severas sanções à Alemanha no período pós-primeira guerra. Desta forma, pensava Hitler “a questão da legalidade assume um papel secundário.” Os resultados desse pensamento dentre outros são a destruição de toda a Europa, parte do Oriente Médio e da África. (HITLER. Apud. CARR, Edward H. Vinte Anos de Crise. 2.ed. Brasília: EdUnb, 2001, p. 240.)
} 
princípio da reciprocidade e proporcionalidade, os prejudicados podem aplicar contraprocedimentos que funcionam como sanções ao país desordeiro.

Porém isso não significa que sempre que um Estado viola o direito ambiental internacional se aplique as mesmas medidas sancionárias do direito tradicional, isto porque nem sempre sanções são favoráveis ao meio ambiente. Hoje os procedimentos instituídos pelo direito ambiental internacional procuram prover assistência e auxiliar os paises violadores da lei ao invés de puni-los, com a certeza de que esse método tradicional de sanções prejudica o meio ambiente. ${ }^{45}$

\subsection{Aplicabilidade da lei}

A lei é condicionada a um critério de avaliação quanto a sua validade, o qual o sistema jurídico tenha definido. Esses critérios são fatores morais que não podem ser esquecidos, mesmo na busca de um objetivo como a proteção ambiental. Nessa linha de pensamento, encontra-se o princípio da soberania e os princípios de proteção ao meio ambiente, princípios historicamente válidos para a comunidade e sociedade internacional, mas que também podem ser limitados por outros princípios válidos, cabendo assim à Hermenêutica analisar o peso de cada princípio quanto a sua aplicabilidade nas ações estatais.

A Soberania é historicamente suprema nas relações internacionais somente até o momento que é acordado entre as partes algo que a limite. A deformação da observância das leis internacionais e princípios compromete a crença no sistema internacional e o funcionamento do sistema de balança de poderes, o que, mais tarde, pode resultar na mudança de regimes e guerras para se restabelecer o direito internacional. Obstruir a Soberania de um Estado em decidir o que é melhor para seus interesses gera conseqüências sociais inaceitáveis.

O risco de não se observar as leis do direito ambiental internacional deve ser reduzido. Faz-se necessária a observância das leis de proteção ao meio ambiente pelos Estados soberanos e pela sociedade internacional dos Estados, ou o sistema de proteção ambiental tenderá ao colapso.

Os direitos à Soberania e à proteção ao meio ambiente são direitos já consagrados pelas instituições internacionais. Apesar de cada um ser limitador do outro, eles são compatíveis quanto a sua formação constituinte. Entende-se que a sociedade transforma-se

\footnotetext{
45 Como exemplo, no Protocolo de Montreal, as Partes que, apesar dos esforços e da boa-fé, não conseguem manter suas obrigações podem recorrer ao Comitê de Implementação, que pode prescrever métodos de auxilio. São esses: assistência no campo cientifico, técnico e financeiro, transferência de tecnologia e treinamento.
} 
constantemente através de mudanças econômicas, culturais, políticas, sociais dentre outras. O reconhecimento de novos valores pela sociedade é uma operação que acaba sendo implementada no ordenamento jurídico. O Direito tenta se amoldar para acompanhar as mudanças sociais. O princípio da soberania é algo provavelmente previsto em todos os ordenamentos jurídicos do Estado Moderno de Direito. Dentro da mesma visão, os novos direitos, como a proteção ao meio ambiente, o desenvolvimento sustentável e, conseqüentemente, a adoção de mecanismos do direito internacional estão sendo reconhecidos como valores fundamentais da humanidade.

Ademais, as dificuldades de relacionamento entre Soberania e meio ambiente são evidenciadas, maiormente, pela política, que, muitas das vezes, prefere outros interesses que aos ambientais. Ou seja, a ascendente dificuldade na implementação brota das dificuldades políticas e, não somente, das legais. Crer que o Direito eliminaria todos os problemas ambientais é ingenuidade, apesar de ele ser a maior ferramenta para tal processo.

\subsection{Considerações}

O homem [...] tem a solene obrigação de proteger e melhorar o meio ambiente para as gerações presentes e futuras. [...] Os Estados devem cooperar para continuar desenvolvendo o direito internacional no que se refere à responsabilidade e à indenização às vítimas da poluição e de outros danos ambientais que as atividades realizadas dentro da jurisdição ou sob o controle de tais Estados causem a zonas fora de sua jurisdição. ${ }^{46}$

A proteção dos ecossistemas é inalienável ao desenvolvimento das nações. A implementação de instrumentos legais se traduz em essencialmente dar eficácia a esses anseios, já que o direito é a principal forma de ação estatal. Precedentemente, viu-se que Soberania traduz-se em poder constituinte, assim sendo, sabe-se que a constituinte expressa o contrato social em que a vontade e os valores de cada sociedade são protegidos. Entendendo e aceitando a proteção do meio ambiente com um desses valores não se tem a limitação absoluta da Soberania pelo direito ambiental, mas a cooperação entre esses dois institutos. O resultado desse processo é a obrigação de cada Estado em promover meios eficazes à proteção ambiental.

Dar proteção legal a esse processo é importantíssimo: envolve implementação de normas e assegura que os Estados venham a cumpri-las. Entretanto, a comunidade internacional não tem poder de polícia. Isso diferentemente dos sistemas internos

\footnotetext{
${ }^{46}$ Princípio 1 e Princípio 22 da Declaração de Estocolmo. . 
impossibilita a implementação de normas e sanções das maneiras como conhecemos em nossos territórios. Destarte, é importantíssima a complacência dos Estados a aderirem a leis internacionais. E é evidente a necessidade de se utilizar mecanismos e técnicas que possam atrair os Estados a anuírem a valores ambientais. Deseja-se que sistemas jurisdicionais nacionais adotem corretamente instrumentos que conduzam a um impacto positivo na proteção do meio ambiente. Existem algumas formas em que se pode conseguir esse objetivo:

Persuasion, the pressure of public opinion, assistance and financial incentives, but also the drafting of good texts and the removal of legal obstacles inside states are the main components of the policy which can ensure compliance with international obligations rather than real sanctions imposed by force. ${ }^{47}$

O fato é que, cada vez mais, as questões jurídicas são alteradas por considerações políticas. O papel do direito ambiental é um efeito estabilizador, no sentido de promover a proteção ao meio ambiente, e, desenvolvimentista, no que se refere à possibilidade de crescimento dos países. O meio ambiente motiva a tomada de consciência da unidade do destino mundial e dos perigos que ameaçam nosso convívio.

Pode-se constatar no cenário internacional que nem sempre as normas são compreendidas da mesma forma e que os Estados tendem a personalizar seus interesses, sendo esse o preceito fundamental do interesse mundial em manter-se o princípio da soberania. Porém deve-se lembrar que interpretações extremistas levaram a inúmeros danos irreversíveis ao meio ambiente, e que para salvaguardar-se o direito das futuras gerações deve-se criar obrigações internacionais para proteger retroativamente seus direitos.

De fato, na origem desses mecanismos de direito internacional, sobretudo nas organizações internacionais, encontra-se um compromisso voluntário dos Estados em se obrigar à proteção ambiental e isso tende a colocar um limite à Soberania absoluta dos Estados. A partir de que os Estados se adentram a esses acordos, eles ficam submetidos às leis dos mesmos, cabendo a essas instituições provocarem os Estados nacionais a anuírem a suas obrigações internacionais.

\section{Instituições disponíveis do sistema ONU para resolução de conflitos ambientais}

\footnotetext{
${ }^{47}$ KISS, Alexandre. Introduction to International Environmental Law. Genebra, Suíça:UNITAR, 1997, p. 57.
} 
O direito internacional tem o encargo, mesmo que não exclusivo, de assegurar a ordem e a segurança nas relações internacionais e fornecer auxílio para se restabelecer esses ideais quando eles são suspensos, baseando-se na justiça procurada pelos indivíduos e realizada, maiormente, pelas organizações internacionais e pelos Estados.

Nesse contexto, o objetivo desta segunda etapa do trabalho é tentar explicar esse tema, enfocando-se os mecanismos oferecidos pelas instituições das Nações Unidas para solução de conflitos de natureza ambiental.

\subsection{O que se entende por conflito ${ }^{48}$}

Conflito Internacional "é uma forma de interação entre indivíduos, grupos, organizações e coletividades que implica choques para o acesso e a distribuição de recursos [...]"49 Pode-se entender que os conflitos sobre questões ambientais são, portanto, os choques em relação à autoridade e ao uso sobre determinado recurso ou sistema ambiental. Em sentido amplo, é toda divergência, oposição ou desacordo sobre qualquer ponto jurídico ou político ${ }^{50}$ dentro das relações internacionais. Portanto, os conflitos podem ser jurídicos e não jurídicos, dependendo de seu tema.

Segundo Rezek, a Corte de Haia conceitua juridicamente conflito como: "conflito ou litígio internacional todo 'desacordo sobre certo ponto de direito ou de fato', toda ‘contradição ou oposição de teses jurídicas ou de interesses entre dois Estados"”. ${ }^{51}$

Dessa forma, ressalta-se que “o conflito internacional não é necessariamente grave ou explosivo, podendo consistir, por exemplo, em mera diferença quanto ao entendimento do significado de certa norma expressa em tratado que vincule dois países.” 52

Tradicionalmente, as correntes doutrinárias do direito internacional público se preocupam com os conflitos gerados entre Estados-Nações, com intenção, prioritária de

\footnotetext{
${ }^{48}$ Este trabalho se referirá a essas formas mais amenas e mais violentas de conflitos aleatoriamente, ora mencionado conflitos amenos, ora conflitos violentos. Também usaremos o termo disputa e controvérsia como sinônimos de conflito.

${ }^{49}$ PASQUINO, Ginafranco In: BOBBIO, Norberto; MATTEUCI,Nicola e PASQUINO Gianfranco. Dicionário de Política. 5.ed. Brasília: Editora Universidade de Brasília, 2000.p.225.

${ }^{50}$ Distingue-se conflito jurídico de político. No primeiro se trava um conflito sobre entendimento e aplicação de uma norma existente e no segundo luta-se pela modificação, criação ou retorno a um direito. ROUSSEAU, Charles Apud: REZEK, José Francisco. Direito Internacional Público: curso elementar. 9.ed. São Paulo: Saraiva, 2002. p 327.

${ }^{51}$ Apud: REZEK, José Francisco. Direito Internacional Público: curso elementar. 9.ed. São Paulo: Saraiva, 2002, p 327.

${ }^{52}$ REZEK, José Francisco. Direito Internacional Público: curso elementar. 9.ed. São Paulo: Saraiva, 2002, p 327.
} 
"preservar as gerações vindouras do flagelo da guerra que, por duas vezes, no espaço de uma vida humana, trouxe sofrimentos indizíveis à humanidade.” ${ }^{53}$. E também porque até este momento os Estados, dentre os demais atores, ainda têm a maior capacidade de agir na esfera internacional.

Contudo, não se pode limitar o cenário internacional à esfera dos Estados e das guerras. A participação de outros atores realmente é restrita se comparada com a dos Estados, entretanto existem inúmeros conflitos entre diferentes sujeitos, como por exemplo: Estado e organização internacional; Estado e indivíduo; organizações internacionais e organizações internacionais; organização internacional e organizações não governamentais, dentre outros.

A Resolução de Conflitos revela-se pela existência de uma oposição de interesses entre as partes, e pela necessidade de se solucionar esse impasse. Quanto a isso, é adequado fazer alusão que "todas as sociedades produzem constantemente em si antagonismos que não nascem casualmente nem podem ser arbitrariamente eliminados” ${ }^{54}$.

Sabe-se que a eliminação total dos conflitos é impossível, uma vez que isso constitui em algo inerente à sociedade. O processo ou tentativa mais freqüente de limitá-los é dar regulamentação aos conflitos, normatizando e estabelecendo padrões de comportamentos. Em outras palavras, afirma-se que:

A tentativa consiste não em pôr fim aos conflitos, mas em regulamentar suas formas de modo que suas manifestações sejam menos destrutíveis para todos os atores envolvidos [...] O ponto crucial é que as regras devem ser aceitas por todos os participantes e, se mudadas, devem ser mudadas por recíproco acordo. Quando um conflito se desenvolve segundo regras aceitas sancionadas e observadas, há sua institucionalização. ${ }^{55}$

\subsection{Regime das Nações Unidas (ONU)}

Define-se regime como: "Instituições sociais que consistem de acordos em princípios, normas, regras, procedimentos e programas que governam as interações dos atores em determinadas áreas [issue areas].” 56

Os regimes internacionais são utilizados para prevenir os conflitos além de desempenhar outros papéis importantes, pois reduzem a incerteza e insegurança, estabilizam

\footnotetext{
53 Referência as duas Grandes Guerras do século XX. Nota Introdutória da Carta das Nações Unidas.

${ }^{54}$ DAHRENDORF. Apud: PASQUINO, Ginafranco In: BOBBIO, Norberto; MATTEUCI,Nicola e PASQUINO Gianfranco. Dicionário de Política. 5.ed. Brasília: Editora Universidade de Brasília, 2000, p.227.

55 PASQUINO, Ginafranco In: BOBBIO, Norberto; MATTEUCI,Nicola e PASQUINO Gianfranco. Dicionário de Política. 5.ed. Brasília: Editora Universidade de Brasília, 2000, p.228.

${ }^{56}$ LEVY, Marc; YOUNG, Oran e ZÜRN, Michael. The Study of International Regimes. [s.l, s.ed], 1995.
} 
as expectativas mútuas futuras, minimizam os custos de transação, produzem informações, prevêem um conjunto e asseguram a repetição das interações.

Como muitos dos conflitos referentes ao meio ambiente envolvem a biosfera ${ }^{57}$, o papel da ONU é imprescindível. A maior parte das composições de leis ambientais internacionais são produções internas da família de organizações e instituições, geralmente, designadas como o "sistema das Nações Unidas." 58

Entendendo a papel das instituições internacionais, o Princípio 25, da Declaração de Estocolmo declara que os Estados “devem assegurar-se de que as organizações internacionais realizem um trabalho coordenado, eficaz e dinâmico na conservação e no melhoramento do meio ambiente.” 59

As Nações Unidas passaram a ocupar um papel fundamental na proteção do meio ambiente a partir de 1968, quando a Assembléia Geral recomendou através de uma proposta do Conselho Econômico e Social o que, mais tarde, tornou-se a Conferência de Estocolmo. Desta nasceu o PNUMA, Programa das Nações Unidas para o Meio Ambiente, órgão quase autônomo das Nações Unidas, peça primordial do sistema da ONU para proteção ambiental. Em benefício do meio ambiente, outros órgãos e agências especializadas da ONU também compõem esse sistema, tais como, CDS, PNUD, UNCTAD, OMS, IMO, AIEA, dentre outros. Assim cabe neste trabalho evidenciar os principais órgãos da ONU, em detrimento de algumas dessas agências especializadas, embora se reconheça que algumas delas são de grande importância para proteção do meio ambiente.

No sistema da ONU, os usos dos meios pacíficos de solução de conflitos são sempre obrigatórios. A Carta da ONU proibiu o uso da força no seu art.2(3), salvo a legítima defesa e determina que todos “os Membros deverão resolver suas controvérsias internacionais por meios pacíficos, de modo que não sejam ameaçadas a paz, a segurança e a justiça internacional.” ${ }^{60}$ De acordo com a Carta da ONU, seus métodos de resolução de conflitos englobam:

As partes em uma controvérsia, que possa vir a constituir uma ameaça à paz e à segurança internacionais, procurarão, antes de tudo, chegar a uma

\footnotetext{
${ }^{57}$ Conceituada como: "a totalidade do meio ambiente humano, a parte até onde se sabe, toda a vida esta concentrada.” (KISS, Alexandre. Introduction to International Environmental Law. Genebra, Suíça:UNITAR, 1997, p.1) (todas as traduções deste trabalho são de total minha responsabilidade.)

${ }^{58}$ SAND, Peter H. The Role of International Organizations in the Evolution of Environmental Law. Genebra, Suíça: Unitar, 1997, p. 19.

${ }^{59}$ Declaração de Estocolmo Sobre o Meio Ambiente Humano, 1992.

${ }^{60}$ Carta das Nações Unidas.
} 
solução por negociação, inquérito, mediação, conciliação, arbitragem, solução judicial, recurso a entidades ou acordos regionais, ou a qualquer outro meio pacífico à sua escolha. ${ }^{61}$

Claramente, as disputas ambientais se aplicam a esses artigos. Como o objetivo deste trabalho é tratar as instituições da ONU para solução de conflitos ambientais, não se discutirá inteiramente os mecanismos descritos no artigo 33 de Carta da ONU. Entretanto, verificar-se-á alguns desses mecanismos, desde que, esses estejam vinculados ao estudo dessas instituições ${ }^{62}$.

\subsection{1 .Instituições para resolução de conflitos ambientais: órgãos políticos da ONU:}

\subsubsection{Conselho de Segurança e a Assembléia Geral}

O Conselho de Segurança pode ser utilizado como instância de conflitos internacionais, desde que observe duas vias: "tal controvérsia ou situação pode constituir ameaça à manutenção da paz e da segurança.” 63

Em qualquer fase de uma controvérsia, de mesma ou semelhante natureza, daquelas a que se refere o $\operatorname{art}^{\circ} .33,{ }^{64}$ o Conselho poderá recomendar procedimentos ou métodos para a solução e quando as partes não conseguirem resolver pelos meios indicados, deverão submeter-se a esse, o qual determinará termos de solução adequados. Levando em consideração o $\operatorname{art}^{\circ} 36^{65}$, mormente deverá tomar consideração que as controvérsias de caráter jurídico devem em regra ser submetidas à Corte Internacional de Justiça.

O Conselho de Segurança, por incumbência de manter a paz, é uma das poucas instituições que tem o poder de obrigar legalmente a obediência de suas decisões. Um exemplo disso é a resolução $687 / 91^{66}$, em que o Conselho demonstrou preocupar-se com o meio ambiente, impondo graves sanções ao Iraque por degradar o meio ambiente do Kuwait. O Conselho também criou a Comissão de Compensações, com uma categoria especial para petições relacionadas ao meio ambiente, aberta a indivíduos, corporações, organizações internacionais e Estados que se achem prejudicados pelas ações do Iraque.

\footnotetext{
${ }^{61}$ Carta das Nações Unidas, artigo 33(1).

62 O Conselho de Tutela da ONU encontra-se inativo desde 1994 e em processo reformulação desde 1997, portanto, não será comentado suas funções.

${ }^{63} \mathrm{Art}^{\circ} 34$ da Carta das Nações Unidas.

${ }^{64}$ Ver, Carta das Nações Unidas.

${ }^{65}$ Ver, Carta das Nações Unidas.

${ }^{66}$ Ver: http://www.un.org/Docs/scres/1991/scres91.htm
} 
A Assembléia Geral dentro do sistema também possui encargos para resolução conflitos internacionais, discutindo questões ou assuntos referentes à Carta, mediante recomendações, estudos, e criação de órgãos especiais e, às vezes, criando comissões de bons ofícios e indicando mediadores em vários casos. No entanto, há temas em que ela tem poder exclusivo, porém não pode fazer recomendações a propósito de controvérsia que esteja sendo tratada pelo Conselho de Segurança, a menos que este a solicite.

A possibilidade de ação cabe a qualquer não membro (com algumas reservas) ou membro da ONU, já que ambos podem solicitar atenção do Conselho de Segurança ${ }^{67}$ e a Assembléia Geral. A Carta faculta acesso dos litigantes e de terceiros, observando-se algumas exceções.

Segundo REZEK, “[a] prática revela que o Conselho de Segurança merece preferência dos reclamantes [...] por estar permanentemente acessível”8, enquanto a Assembléia se reúne periodicamente.

\subsubsection{Secretariado Geral}

O Secretariado é um órgão interno da ONU que presta serviços, em todo o globo, aos demais órgãos da organização e administra os programas e políticas que esses elaboram. Essa missão resulta em funções como a de administrar mediações internacionais entre partes conflitantes (ex. Conciliação no caso Rainbow Warrior, 1986), e, nesses casos, utiliza-se o Escritório de Assuntos Legais (OLA), que se trata de um departamento interno do secretariado. Em outras palavras, o Secretariado possui poder de exercer a função diplomática de solução de conflitos.

\subsubsection{Conselho Econômico e Social}

O Conselho Econômico e Social, inter alia, formula recomendações, cria resoluções legais (ex. 713, XXVII) e inicia atividades relacionadas ao trabalho econômico e social da ONU além de coordenar as agências especializadas e as demais instituições integrantes do Sistema da ONU. Dentre essas instituições estão algumas agencias, jointventures, órgãos e instituições auxiliares que em conjunto são imprescindíveis para a

\footnotetext{
${ }^{67}$ Ver Art $^{\circ}$ 35;(1),(2) da Carta das Nações Unidas e a art ${ }^{\circ}$ da Convention on the prohibition of military or any hostile use of environmental modification techniques, 10 de dezembro de 1976.

${ }^{68}$ REZEK, José Francisco. Direito Internacional Público: curso elementar. 9.ed. São Paulo: Saraiva, 2002, p.337.
} 
resolução de conflitos ambientais, tais como, PNUMA, OMC, Banco Mundial, PNUD, AIEA, OMI, CDS, GEF, ILC. O ECOSOC, como também é conhecido, convoca conferências internacionais e prepara projetos de convenções para apresentação à Assembléia Geral sobre assuntos de sua competência, por meio de seus comitês. São eles: Programas e Coordenação, Organizações Não-Governamentais, Negociando com Organismos Intergovernamentais, Recursos Humanos, Recursos Naturais, Ciência e Tecnologia para o Desenvolvimento e Comitê de Exame e Avaliação.

\subsubsection{Corte $^{69}$ Internacional de Justiça ${ }^{70}$}

A Corte é o principal órgão jurisdicional da ONU e possui duas atribuições: exerce sua competência mediante aplicação do direito internacional, julgando litígios entre Estados soberanos, e emite opiniões consultivas sobre questões legais a pedido do Conselho de Segurança, Assembléia Geral e outros órgãos ou entidades especializadas que a Assembléia tenha autorizado a requerer pareceres. Na primeira atribuição, apenas os Estados podem requerer sua comarca, e, tão somente, se ambas as partes aceitarem sua jurisdição descrita em seu Estatuto Interno. A segunda é exclusividade de organizações internacionais. Em peculiar, para as questões ambientais a CIJ criou um câmara especial composta de sete membros.

A carta da ONU confere poderes a CIJ em decidir acerca de controvérsias jurídicas. ${ }^{71}$ A Agenda 21 incentiva a utilização da Corte em disputas ambientais ${ }^{72}$ e a Estatuto da Corte confirma esta competência ${ }^{73}$. Ou seja, quando se refere à resolução judicial de controvérsia , normalmente, subentende-se uma sentença da Corte. As decisões da CIJ, para as partes envolvidas, são sempre obrigatórias e devem ser obedecidas. Apesar delas não serem obrigatórias para os demais países, a autoridade moral da Corte é tão grande que se considera suas atuações como expressões legítimas do Direito costumeiro internacional.

\footnotetext{
$69 *$ Tribunal, em Portugal.

${ }^{70}$ Informações disponíveis em: http://www.icj-cij.org/icjwww/igeneralinformation/icjgnnot.html

${ }^{71} \mathrm{Arts}^{\circ}$ 36(3) e 33(1).

${ }^{72}$ Agenda 21, capítulo 39:10.

${ }^{73} \mathrm{Art}^{\circ}$

disponível

em:

< http://www.interlegis.gov.br/processo_legislativo/copy_of_20020319150524/20030616104212/20030616131 $\underline{926 / \text { view }>}$
} 
Algumas decisões da CIJ foram importantes para a defesa do meio ambiente, quando essa declarou que: “os Estados têm a obrigação de respeitar e proteger a natureza” ${ }^{74}$, a retroatividade dos direitos das futuras gerações, e que o meio ambiente é um 'interesse essencial' dos Estados. Destarte, a Corte consolida a visão de que o Direito internacional proíbe os danos ao meio ambiente, expressando que no campo da proteção ambiental é necessário: a vigilância e a prevenção, pelo fato de que esses danos podem ser irreversíveis à biosfera. ${ }^{75}$

\subsubsection{Tribunal Internacional Sobre Direito do Mar}

A Parte XV Convenção das Nações Unidas sobre Direito do Mar exige que os Estados resolvam seus conflitos segundo a Carta da ONU, através dos dispositivos do $\operatorname{art}^{\circ} 33$. E ainda estipula no $\operatorname{art}^{\circ} 286$ e 287 a possibilidade das partes em consenso requererem a intervenção da Corte Internacional de Justiça; do Tribunal Internacional Sobre Direito do Mar (anexo VI da Convenção); da Corte Internacional de Justiça; a um tribunal arbitral especial (constituído segundo o anexo VII da Convenção). Caso não haja consenso entre as partes, o $\operatorname{art}^{\circ} 287$ afirma que será utilizada a arbitragem tradicional.

O Tribunal Especial é normalmente empregado quando questões técnicas específicas estão sendo abordadas e especialistas nas áreas são indispensáveis. A Convenção proclama que esse método seja utilizado para as questões acerca de pesca, meio ambiente marinho e poluição marítima. As listas de especialistas devem ser mantidas regularmente pelas agências especializadas da ONU: a ANUAA, PNUMA, IMO e COI (da UNESCO).

A Jurisdição do Tribunal sobre Direito do Mar é prevista na CNUDM, em questões relativas aos oceanos. Quanto ao entendimento e à aplicação da Convenção até mesmo nas questões relativas a conflitos, além de julgar, serve como órgão consultivo para o Conselho de Segurança e Assembléia Geral. O papel mais importante do Tribunal é a resolução de conflitos entre Estado referente à proteção ambiental. ${ }^{76}$

\footnotetext{
${ }^{74}$ Apud. Order of September of 1995 in Request for an Examination of the Situation in Accordance with paragraph 63 of the Court's Judment of December 1974 in the Nuclear Tests Case, I.C.J Reports, p. 306.para. 64. KISS, Alexandre; SHELTON, Dinah. International Environmental Law. Ardsleu, New York:Transnational Publishers, 2004, p.182. (Trad.minha. responsabilidade)

${ }^{75}$ KISS, Alexandre; SHELTON, Dinah. International Environmental Law. Ardsleu, New York:Transnational Publishers, 2004, pp.182-183.

${ }^{76}$ KISS, Alexandre; SHELTON, Dinah. International Environmental Law. Ardsleu, New York: Transnational Publishers, 2004, p.183.
} 
Os procedimentos do Tribunal são abertos aos Estados signatários e faculta em caráter especial, suas instâncias para Organizações internacionais. Dependendo do caso, para acionar o Tribunal, utiliza-se uma notificação, um acordo especial com o Tribunal ou uma Carta de Motivos. As ações podem ser movidas contra qualquer organização estatal, pessoas jurídicas e civis, Estados, Organizações Internacionais, ou qualquer parte de um contrato. Destaca-se que a informação de que os custos do processo devem ser pagos pelas partes, salvo quando o Tribunal declarar o contrário.

\subsubsection{Considerações}

Muitos tratados internacionais especificam que controvérsias devem ser encaminhadas a CIJ ou resolvido por arbitragem. A Corte formou uma câmara especial para assuntos ambientais. Mas o fato é que nem sempre se utiliza o sistema da ONU para resolução de conflitos ambientais. Uma das explicações para isto é que muitos tratados e conferências possuem seu mecanismo autônomo para resolução de conflitos. Outra explicação é que antes dos conflitos se tornarem conhecidos, ou chegarem às cortes internacionais, os Estados preferem pagar compensações às vítimas e julgar qualquer litígio em seus próprios tribunais internos. Sendo assim, o Estado não perde sua credibilidade internacional, não é visto com desagrado pelos demais Estados e pela opinião pública, podendo contornar a situação internamente. Esse processo é chamado de “dispute avoidance,”, pois minimiza as disputas judiciais e a arbitragem internacional.

Todavia, conclui-se que a “família da ONU” possui mecanismos competentes para julgar litígios ambientais internacionais. Seus órgãos, agências especializadas e joint-ventures são as peças internacionais fundamentais para a prevenção e proteção do meio ambiente, trabalham e administram em coordenação à criação e aplicação das normas de Direito Ambiental Internacional, auxiliando os atores internacionais em conflitos e construindo um regime que almeja o desenvolvimento sustentável, a paz e a segurança.

\section{Conclusões ${ }^{77}$}

\footnotetext{
${ }^{77}$ É importante frisar que esse artigo não buscava analisar através de paradigma exclusivo de uma escola teórica das relações internacionais. De fato os autores majoritários foram da escola realista quando se analisou a atual conjuntura, entretanto neste trabalho, não foi proposta a reconstrução política através de idéias de qualquer escola em particular.
} 
Este artigo teve por objetivo analisar a atual conjuntura da ordem ambiental internacional, descrevendo primeiramente o conflito entre o conceito de soberania e a responsabilidade dos Estados na proteção ambiental. Concluímos, de acordo com o princípio 21 da Declaração de Estocolmo, que o direito soberano dos Estados é sujeito a duas restrições: primeiro, os Estados não devem extrapolar as margens dos princípios consagrados pelo Direito Internacional, principalmente não violar a Carta da ONU. Em segundo, os Estados possuem a obrigação de controlar atividades em sua jurisdição e não somente em sua jurisdição como também nas áreas de proteção em conjunto, como o alto mar, o espaço sideral, e a Antártica.

Essa é a dicotomia que os Estados enfrentam na ordem internacional. A respeito das obrigações internacionais e soberania afirma que:

[...] a doutrina da soberania, que conservou a sua importância ao longo do período moderno da historia, concedeu ao Estado democrático nacional, com a concepção da soberania popular, uma poderosa arma política. Mas, também esteve sujeita a revisões, reinterpretações e ataques, especialmente na área do direito internacional. A fonte dessas dúvidas e dificuldades residem na aparente incompatibilidade lógica entre duas premissas do direito internacional moderno: a presunção de que o direito internacional impõe restrições legais às nações individuais e a presunção, de que essas mesmas nações soberanas - isto é, autoridades com poderes para criar leis e faze-las cumprir - embora elas próprias não estejam sujeitas a restrições legais. ${ }^{78}$

Além do mais, neste artigo, nitidamente se verificou que a atual crise ambiental é global, entretanto, a governança não é global. A despeito do que se viu sobre o suposto conflito entre soberania e proteção ambiental, o novo rumo do direito ambiental utiliza-se do princípio da descentralização, a gestão ambiental é contida na esfera micro, toda gestão é feita no nível mais hierárquico mais baixo da sociedade. Somente quando a esfera do problema excede a capacidade individual deve-se procurar soluções em níveis hierárquicos mais altos, até a última instância, podendo se alcançar a gestão global, se necessário. Assim sendo, a gestão do meio ambiente transita entre mecanismo dentro das estruturas soberanas e fora delas na ordem internacional. Destarte, observa-se que os instrumentos internacionais não procuram desfazer o princípio da soberania, mas tão somente criar novos mecanismos de gestão e responsabilidade em conjunto para melhor gestão e proteção ambiental, quando os Estados individualmente não podem proteger o meio ambiente.

\footnotetext{
${ }^{78}$ MORGENTHAU. A Política entre as Nações. Brasília: Edunb, 2003, p.569. 
Um exemplo desse processo de descentralização ambiental é a Convenção do Rio sobre a Diversidade Biológica (CBD). O texto dessa convenção institui o Estado como único titular do acesso aos seus recursos. Todavia, atribuem papel complementar à comunidade tradicional e local, além do mais atribui responsabilidades comuns, porém diferenciadas aos Estados.

Alguns autores, autoridades estatais, principalmente os mais conservadores, entendem isso como algo deturpador do direito internacional, todavia devemos lembrar mais uma vez que esse processo é semelhante ao que aconteceu ao direito da guerra e ainda acontece com os direitos humanos. Por exemplo, hoje, ao contrário da visão majoritária prégrande guerra, se defende a guerra como um instrumento de justiça que deve ser limitado pela lei das nações. Assim como os direitos humanos foram transformadores do viés tradicional do direito internacional, principalmente após a segunda guerra, a direito ambiental ocupa um local similar.

Contudo, segundo Kiss, nenhum juiz condenaria um país por não tomar as devidas providências para melhoria do meio ambiente global, embora pudesse condenar um Estado que viole leis e (ou) causem dano ao meio ambiente de outra pátria. Aliás, o que difere sua visão é quando ele define "responsabilidade”. Para ele a responsabilidade é um conceito de teor moral/político muito mais do que um conceito legal, isto é, responsabilidade é uma obrigação moral. ${ }^{79} \mathrm{O}$ que podemos concluir dessa afirmação é que a "responsabilidade ambiental” por parte dos Estados é de teor político, e não totalmente legal. É de fato uma obrigação natural, fruto dos ideais éticos humanos. Ou seja, são tentativas políticas, em boa fé, para solução de problemas ambientais, as quais respeitam a soberania, porém modificam sua essência para um bem maior.

Há que se lembrar que os tratados, confiando-se na boa-fé e nos costumes, devem ser: pacta sunt servanda. Portanto isso não tira a obrigação de se obedecer a normas válidas e deve-se lembrar que toda norma é a imagem que se quer de um mundo melhor, ou seja o “dever ser”.

A segunda parte do trabalho examinou-se de forma descritiva as principais instituições da família ONU para solução de controvérsias. É verdade que mesmo existindo a interdependência entre as nações, inevitavelmente, conflitos irão surgir e mecanismos para

\footnotetext{
${ }^{79}$ KISS, Alexandre. Introduction to International Environmental Law. Genebra, Suíça: UNITAR, 1997, p.112. 
solução desses é importantíssimo. Também se concluiu que muitas deles não são utilizadas pela preferência da descentralização dos Estados em resoluções de controvérsias.

Embora a ordem ambiental internacional seja globalizada, e não obstante o conceito de interdependência seja algo relacionado com a economia, é verdade que a questão ambiental também é transnacional e utiliza-se de regimes internacionais para governança global. O fato é que os países respeitando sempre a Soberania devem cooperar com a proteção ambiental, entretanto, os interesses dos Estados são tão inúmeros quantos os problemas ambientais e os mecanismos para se colocar em pauta na agenda internacional questões ambientais, é dificílimo já que o atual sistema econômico se beneficia da atual ineficácia na proteção do meio ambiente. É verdade também que as questões de segurança e economia possuem preferência na agenda internacional. O paradoxo central deste trabalho é este: os paises buscam seus próprios interesses soberanos, notam a responsabilidade de cooperarem para proteger o meio ambiente, encaminham recursos para a criação de instituições que criem normas e mecanismo ambientais, que limitam de certa forma a soberania, entretanto se deparam com uma ordem internacional ineficaz e frágil. Ao se depararem com a dificuldade dessa ordem, seus esforços são imediatamente direcionados para questões os possibilitem ganhos imediatos, tais como o comercio exterior e segurança. Esse contraditório entre cooperação e interesses individuais só pode ser solucionado com a concepção de novos mecanismos ambientais ou uma nova ordem mundial.

Artigo recebido em outubro de 2006

Aceito para publicação em fevereiro de 2007

\section{Referências}

BAPTISTA, Zulmira Maria de Castro. O Direito Ambiental Internacional: Política e Conseqüências. São Paulo: Editora Pillares, 2005.

BOBBIO, Norberto; MATTEUCI, Nicola e PASQUINO Gianfranco. Dicionário de Política. 5.ed. Brasília: Editora Universidade de Brasília, 2000.

CARR, Edward H. Vinte Anos de Crise. 2.ed.Brasília: EdUnb, 2001. 
CONFERENCIA DAS NAÇÕES UNIDAS. Declaração de Estocolmo Sobre Meio Ambiente Humano. Junho de 1972

DUPUY, René-Jean. O Direito Internacional. Coimbra, Almedina, 1993.

MORGENTHAU, Hans J. A Política entre as Nações: A luta pelo poder e pela paz. Brasília: Unb, 2003.

KEOHANE, Robert; NYE, Joseph. Power and Interdependece. 3.ed. London, Logman, 2001.

KISS, Alexandre. Introduction to International Environmental Law, Genebra, Suíça: UNITAR, 1997.

KISS, Alexandre e SHELTON, Dinah. Developments and Trends in International Environmental Law. Genebra, Suíça: UNITAR, 1999.

KISS, Alexandre; SHELTON, Dinah. International Environmental Law. Ardsleu, New York: Transnational Publishers, 2004.

LASSALE, Ferdinand. A Essência da Constituição. 4.ed. São Paulo: Lúmen Iuris, 1998.

LEVY, Marc; YOUNG, Oran;ZÜRN, Michael. The Study of International Regimes. [s.l, s.ed], 1995.

MATTOS, Adherbal Meira. Direito, Soberania e Meio Ambiente. Rio de Janeiro, Destaque, 2001.

REZEK, José Francisco. Direito Internacional Público: curso elementar. 9.ed. São Paulo: Saraiva, 2002.

SAND, Peter H. The Role of International Organizations in the Evolution of

Environmental Law, Course 2. Genebra, Suíça: Unitar, 1997.

SÃO FRANCISCO. Carta das Nações Unidas. Junho, 1945.

VIEIRA, Danilo Porfírio de Castro. Os Contratos na Gênese do Direito. Brasília: Editora Juarez de Oliveira, 2004.

VIOTTI, Paul R; KAUPI, Mark V. Internacional Relations Theory: Realism, Pluralism, Globalism, and Beyond. 3. ed. Boston:Prentice Hall, 1998.

VIENA. Convenção de Viena Sobre Direito Dos Tratados. Maio,1969. 


\section{Resumo}

Este artigo tem como objetivo analisar o choque entre o princípio da soberania estatal e a responsabilidade dos Estados em proteger o meio ambiente. Faz-se um exame da adaptação do direito tradicional às novas necessidades de gestão ambiental. Examina-se também neste artigo as instituições competentes da ONU para resolução de litígios ambientais internacionais. Finalmente, o artigo faz uma leitura sucinta do processo da governança global.

Palavras-chave: Direito Ambiental Internacional. Meio Ambiente. Soberania. Relações Internacionais.

\begin{abstract}
This article analyzes the principle of State sovereignty when confronted with international environmental obligations. By analyzing these two concepts, it is possible to examine how traditional international law has adapted to the demands of environmental interdependence. There is also the analysis of the main institutions of the U.N. system that are available for environmental dispute settlement. Finally, this article briefly examines, the matter of global governance.
\end{abstract}

Keywords: International Environmental Law. Environment. Sovereignty. Foreign Affairs. 